\title{
AS CONTRIBUIÇÕES LATINO-AMERICANAS PARA A TEORIA CRÍTICA DE DESENVOLVIMENTO
}

\author{
Cristóbal Kay*
}

\begin{abstract}
Neste artigo, exploro a genealogia da contribuição crucial que os cientistas sociais latino-americanos fizeram para os estudos de desenvolvimento durante a segunda metade do século XX. Os estruturalistas contestaram a teoria convencional do comércio internacional, que havia sido proposta pelos teóricos do norte. Os teóricos da dependência criticaram as interpretações ortodoxas do subdesenvolvimento, como as propostas pelos teóricos da modernização, também principalmente do Norte. Aponto duas vertentes da teoria da dependência. Uma emergiu do processo de autocrítica de estruturalistas, e a outra teve suas raízes no marxismo crítico. Com o surgimento do neoliberalismo, alguns estruturalistas de dependência desenvolveram o neoestruturalismo, enquanto alguns dependentistas marxistas desenvolveram a teoria do sistema mundial. As idéias de pensadores estruturalistas e de dependência geraram debates acirrados, capazes de desafiar suas teorias ortodoxas, centradas no Norte, e de propor uma teoria alternativa do desenvolvimento do Sul.

PALAVRAS-CHAVE: Estruturalismo. Colonialismo interno. Marginalidade. Teoria da dependência. Neoestruturalismo.
\end{abstract}

\section{INTRODUÇÃO}

Pode-se argumentar que uma das origens dos estudos críticos sobre desenvolvimento na América Latina são os escritos do marxista e peruano José Carlos Mariátegui (Cf. Mariátegui, 1971). Seus principais escritos foram publicados entre o final dos anos 1920 e o começo dos anos 30, nos quais argumenta que a classe feudal de proprietários de terra e a burguesia nacional, aliadas ao imperialismo, reproduziram continuamente o sistema de exploração e dominação. Ele não acreditava que a burguesia nacional era capaz de representar o papel progressista que havia sido conquistado na Europa. Consequentemente, advogou em prol de uma revolução socialista para alcançar a libertação de classes oprimidas e, em particular, dos povos indígenas. Ao contrário de muitos pensadores contemporâneos, ele previu o potencial revolucionário dos camponeses indígenas. Foi um dos primeiros marxistas que ten-

* Erasmus University Rotterdam. Instituto Internacional de Estudos Sociais (ISS).

Kortenaerkade 12, 2502 LT The Hague, The Netherlands. kay@iss.nl tou adaptar a teoria de Marx para a realidade latino-americana a partir de seu entendimento e em rompimento com o pensamento eurocêntrico (Cf. Kay, 1991; Quijano, 2000). Nesse sentido, Mariátegui previu o estruturalismo e a teoria da dependência, que considero as maiores contribuições para as teorias críticas sobre desenvolvimento que emanaram no continente latino-americano (Cf. Seabra, 2016a). Contudo, enquanto o estruturalismo, em sua crítica à ortodoxia econômica e ao desenvolvimentismo, somente buscou reformar o capitalismo, a vertente marxista, dentro da teoria da dependência, orientou-se para derrubá-lo, com o objetivo de alcançar o socialismo. A análise de Mariátegui, em relação aos povos indígenas e à questão da terra, também constitui uma previsão, em alguns aspectos, das análises dos conceitos de "colonialismo interno" e "marginalidade", que abordarei neste artigo.

Embora o debate sobre "revolução ou reforma” já emergisse nas primeiras décadas do século XX, adquiriu particular intensidade após a Revolução Cubana em 1959 (Cf. Petras; Zeitlin, 1968). Diversos governos, na América Latina e no Caribe, seguiram, de maneira 
limitada, algumas das políticas recomendadas pelo estruturalismo durante as décadas de 50 , 60 e começo dos anos 70, enquanto a teoria da dependência teve muito menos influência nas políticas públicas naquela época, apesar de ela ser bastante popular entre estudantes, partidos de esquerda e movimentos sociais revolucionários. Com a ascensão da contrarrevolução na teoria crítica (Cf. Toye, 1987) no fim da década de 70 e começo dos anos 80, as idéias neoliberais ganharam proeminência e moldaram políticas governamentais não apenas no mundo em desenvolvimento, mas também em países desenvolvidos. Foi apenas a partir do começo dos anos 1980 que os pensadores estruturalistas foram capazes de reagir ao desafio neoliberal, ao propor estratégias de desenvolvimento neoestruturalistas, como será discutido posteriormente. $\mathrm{O}$ artigo termina com algumas breves conclusões, destacando a significância dessas teorias críticas de desenvolvimento que emanaram da América Latina para os estudos de desenvolvimento (Cf. Munck; O’Hearn, 1999; Nederveen-Pieterse, 2001).

\section{TEORIA ESTRUTURALISTA DO DESENVOLVIMENTO}

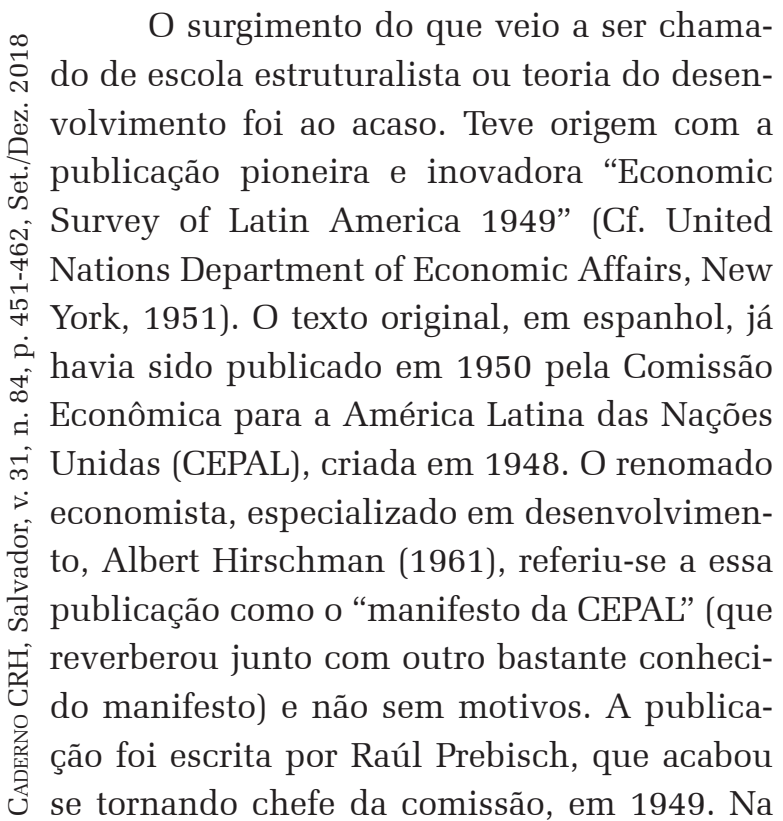

sua análise, ele desafia a ortodoxia econômica da época, que argumentava, com base na teoria das vantagens comparativas, que o comércio internacional era benéfico para as nações envolvidas, especialmente para os países menos desenvolvidos. Prebisch argumentou que, através do comércio, aumenta-se a desigualdade de renda, ao invés de diminuir. Tal conclusão obteve consequências explosivas nas relações entre os países ricos e pobres, não sendo, portanto, surpreendente que Prebisch tenha sido atacado e vilipendiado pelos poderosos, particularmente nos países centrais (Dosman, 2008). Porém Prebisch soube como defender a si e a instituição que conduzia. Ele, de fato, havia montado, liderado e inspirado uma equipe multinacional de cientistas sociais extraordinariamente talentosos (Cf. Furtado, 1964; Kay, 2005).

Prebisch dividiu o mundo entre países centrais e periféricos, o que, em geral, correspondia à terminologia convencional de países desenvolvidos e menos desenvolvidos, ou em desenvolvimento, respectivamente. Ao usar essa terminologia, Prebisch já estava destacando a assimetria de poder entre as nações do mundo. Usando estatísticas históricas, ele descobriu que as tendências de longo prazo dos termos de troca entre a América Latina (a periferia) com os seus principais parceiros comerciais, principalmente os Estados Unidos e a Europa (o centro), estavam deteriorando. A América Latina foi quase exclusivamente exportadora de produtos primários, como minerais e commodities agrícolas, para os países do centro, enquanto importava deles grande parte das commodities manufaturadas. Durante a flutuação dos termos de troca ao longo do tempo, a tendência era negativa para a periferia, o que significava, nos cíclicos de expansão, que o valor das commodities exportadas pela periferia aumentava menos que o preço daquelas importadas pela periferia, e o oposto acontecia durante a queda cíclica. Consequentemente, a deterioração dos termos de troca contra a periferia e em favor do centro contrariava o que a teoria ortodoxa do comércio in- 
ternacional sustentava. Isso significa, dito de maneira mais direta, que a periferia tinha de exportar uma quantidade crescente de commodities primárias para ser capaz de importar a mesma quantidade de commodities industriais dos países centrais. Isso significava, portanto, uma troca desigual. Prebisch não afirmava que o comércio internacional era necessariamente negativo para a periferia, mas sim que os frutos da troca entre as nações favoreciam mais o centro (Cf. Kay, 2006b). Essa tese é conhecida como a "tese Prebisch-Singer sobre a deterioração dos termos de troca" e tem gerado muita controvérsia desde então (Cf. Toye, J.; Toye, R., 2004). Dada a pioneira conceitualização feita por Prebisch das relações entre centro e periferia, alguns autores, de uma maneira geral, se referem ao estruturalismo como o paradigma centro-periferia nos estudos sobre desenvolvimento (Cf. Rodríguez, 1977).

A lição tirada dessa descoberta por parte de Prebisch e sua equipe, na CEPAL, foi a de que a periferia deveria mudar a sua estratégia de desenvolvimento, do "para fora" em direção ao "para dentro". Isso teria de ser feito a partir dos estados da periferia, ao promoverem a industrialização através de vários meios, como o protecionismo, os subsídios e os investimentos em infraestrutura para as nascentes indústrias, um processo que se tornou conhecido como "substituição de importações". O objetivo era reduzir a dependência em exportações de produtos primários e transformar o centro de gravidade da economia para a indústria e os mercados internos. Diversos governos, não só na América Latina, seguiram uma estratégia de desenvolvimento de substituição de importações entre as décadas de 1950 e 70, o que deu origem ao denominado "desenvolvimentismo de estado", dada a centralidade assumida pelos entes estatais nesse processo. Essa estratégia foi bastante criticada por economistas ortodoxos e amplamente derrubada pela onda neoliberal dos anos 80, como será discutido posteriormente.

Outro importante legado da escola estruturalista diz respeito à inflação, que atormen- tou alguns países latino-americanos durante décadas. Novamente, essa interpretação particular das causas da inflação desafiou a posição ortodoxa e gerou debates intensos. Tal debate se tornou conhecido como o debate "monetário-estruturalista" sobre a inflação. Ao invés de enfatizar os fatores monetários, os estruturalistas cepalinos se debruçaram no que eles chamaram de fatores estruturais subjacentes ao fenômeno inflacionário, como a ineficiência do setor agrícola em aumentar a oferta de comida para satisfazer à demanda crescente, desse modo aumentando o preço dos alimentos, causando uma demanda por aumento dos salários dos trabalhadores, e assim por diante, criando uma espiral inflacionária. A culpa por essa falta de resposta, no que se refere à inelasticidade da demanda, segundo os estruturalistas, está no sistema desigual de posse de terras e na atitude rentista de proprietários de terra. Outro fator estrutural surgiu do contínuo déficit de balança comercial, o que requereu desvalorização da moeda local, de maneira a aumentar o preço de produtos importados. Esse desequilíbrio no comercio internacional resulta não somente na deterioração dos termos de troca, mas também em algo característico na política de substituição de importações: crescente demanda de importações de insumos, maquinaria e equipamentos, que foram incapazes de entrar no mercado de exportações. No setor agrícola, as exportações também não cresceram rápido o suficiente. Todos esses gargalos estruturais foram penetrados na estrutura de diversos países. Essa espiral inflacionária, consequentemente, não poderia ser solucionada meramente por meios monetários, como a restrição de moeda; deveria ser encarada com reformas estruturais, como a reforma agrária e uma política de substituição de importações mais competitiva e voltada para exportações. Portanto, os estruturalistas afirmavam que a receita monetarista de se enfrentar a inflação apenas combatia os fatores de propagação, e poderiam prejudicar a economia ao atingir diretamente o crescimento (Cf. Sunkel, 1960). 
Além disso, o que considero notável é a interpretação do economista estruturalista Noyola (Cf. Noyola, 1956), que também introduziu uma dimensão social e política no debate, enfatizando que as pressões inflacionárias surgiram também como consequência da luta de classes entre trabalhadores e capitalistas e proprietários. Enquanto proprietários buscavam aumentar sua apropriação do aluguel de terras aos camponeses e trabalhadores rurais, e os capitalistas seus lucros, ao arrochar salários de trabalhadores, aqueles afetados resistiam à opressão, demandando menores aluguéis e maiores salários, respectivamente. Devido ao poder econômico dos proprietários e capitalistas, qualquer concessão dada aos trabalhadores e camponeses era repassada aos consumidores, aumentando os preços, e contribuindo para o processo inflacionário. Por conseguinte, para a perspectiva estruturalista, domar a inflação também requeria um novo pacto entre as forças sociais em conflito. Em resumo, uma distribuição de renda mais equitativa é necessária. Essa questão da equidade se torna um componente importante para os pensadores neoestruturalistas do desenvolvimento, o que será discutido mais adiante.

A análise de Prebisch das relações desiguais entre centro e periferia o levou além da $\infty$ CEPAL. Ele foi a principal força motriz da criação da UNCTAD, Conferência das Nações Unidas sobre Comércio e Desenvolvimento, que foi estabelecida em 1964 em Genebra, com o objetivo de negociar relações comerciais mais justas entre os países desenvolvidos e os países em desenvolvimento. Prebisch se tornou o primeiro Secretário-Geral da Conferência, porém renunciou em 1969 por não conseguir avançar em seu objetivo de estabelecer uma nova ordem econômica internacional. Realmente, tratava-se de um objetivo muito ambicioso, que permanece descumprido até hoje (Cf. Toye, J.; Toye, R., 2004). O crescimento de Taiwan e da Coréia do Sul, nos anos 70 e 80, e a subsequente ascensão, nas últimas décadas, da China e de outros países da antiga periferia, esteve e está remodelando as relações entre o centro e a periferia, porém não exatamente do jeito que Prebisch e os estruturalistas desejavam, já que o contexto da mudança se dá na era da globalização neoliberal.

\section{COLONIALISMO INTERNO, MARGI- NALIDADE E O SETOR INFORMAL}

Embora a perspetiva estruturalista tenha sido articulada pelos economistas do desenvolvimento, as análises sobre "colonialismo interno" e "marginalidade" envolveram principalmente antropólogos, sociólogos e cientistas políticos. Elas são, portanto, um enriquecedor complemento ao estruturalismo e, na minha visão, podem ser consideradas parte integrante dele, pois também criticam a teoria ortodoxa de modernização ao afirmarem que o colonialismo interno e a marginalidade (na sua variante marxista) são resultados da pretérita dominação imperialista e da atual integração com o sistema-mundo capitalista, respectivamente. Esse fenômeno tem, portanto, características específicas dentro do contexto dos países da periferia, em contraste com os países do centro, que dominam o sistema.

O colonialismo interno se refere à dominação, exploração e discriminação de povos indígenas pelos conquistadores ibéricos e, após as independências, durante as primeiras décadas do século XIX, pelas populações brancas e mestiças (Cf. Cotler, 1967; González Casanova, 1965; Stavenhagen, 1965). Ele tem, portanto, a virtude de focar no sofrimento dos povos indígenas, que vêm sendo amplamente negligenciados pelos estudos de desenvolvimento. Os estudos sobre colonialismo interno também começaram a explorar as conexões complexas e envolventes entre etnia e classe (Cf. Kay, 1989).

A marginalidade refere-se ao impacto do processo de substituição de importações, que se tornou a estratégia de desenvolvimento tomada pela maioria de países latino-americanos 
(assim como outros países em desenvolvimento), inicialmente dentro da classe trabalhadora, (Cf. Nun, 1969) e posteriormente nos camponeses (Cf. Quijano, 1974, 1983; Stavenhagen, 1970, 1980). Ao contrário de antigas experiências em países desenvolvidos, a industrialização não criou tantos postos de trabalho quanto era esperado. Ademais, também contribuiu para o desemprego, ao destruir oficinas locais e empresas incipientes, que foram incapazes de concorrer com a moderna tecnologia importada das novas indústrias. De maneira similar, a introdução de novas tecnologias agrícolas, especialmente a mecanização, fez com que menos trabalhadores fossem necessários e que os pequenos camponeses fossem substituídos, já que não eram capazes de competir com as fazendas capitalistas modernas. Isso levou a um processo de "proletarização", e a crescente migração rural se deu principalmente para favelas urbanas, que não eram capazes de empregar a crescente oferta de trabalho (Cf. Lomnitz, 1977). As altas taxas de crescimento populacional na época só pioraram a situação para os trabalhadores. O conceito de marginalidade, mais tarde, se uniu com o conceito de setor informal (Cf. Tokman, 1978).

Assim como acontece com a marginalidade, existem diferentes conceituações de setor informal. Na estruturação teórica ortodoxa da modernização, esse fenômeno é apenas uma etapa intermediária dos países em desenvolvimento. Já estruturalistas e especialmente marxistas argumentam que a evolução do capitalismo em países em desenvolvimento recria um excedente populacional que necessita buscar maneiras de se sustentar sob as mais precárias e vulneráveis condições. Para a classe capitalista, esse excedente constitui uma oferta constante e segura de mão de obra barata e flexível, de acordo com as suas necessidades. A diferença entre estruturalistas e marxistas reside, principalmente, nas soluções para superar esse fenômeno.

\section{TEORIA DA DEPENDÊNCIA}

A teoria da dependência é uma perspectiva crítica fundamental que surgiu a partir da crítica e da desilusão com o processo de substituição de importações. Não estou me referindo aqui às críticas feitas por economistas ortodoxos e neoliberais (mais sobre isso em breve), mas às críticas que emergiram tanto de estruturalistas como de marxistas. Dentro da teoria da dependência, portanto, é possível identificar, pelo menos, duas vertentes: a estruturalista e a marxista. Apesar das diferenças, ambas compartilham da mesma premissa, de que o processo de desenvolvimento de países emergentes pode ser entendido apenas no contexto das relações com os países desenvolvidos. Tal como formulado por Osvaldo Sunkel (1972, p. 17) a partir de uma perspectiva estruturalista: "O desenvolvimento e o subdesenvolvimento podem, portanto, ser entendidos como estruturas parciais, porém interdependentes, que formam um único sistema”. Da mesma forma, para André Gunder Frank (1966, p. 18), de uma perspetiva marxista: "Em grande parte, o subdesenvolvimento contemporâneo é o produto histórico das relações econômicas passadas e contínuas entre os países subdesenvolvidos e as metrópoles, agora desenvolvidas".

Nessa relação interdependente, os países desenvolvidos são os dominantes, enquanto os países em desenvolvimento estão em uma situação de dependência. Tal dependência tem origens históricas no colonialismo e no imperialismo, porém persistem até os dias atuais, por diversos fatores. A diferença principal entre as duas vertentes está nas ferramentas analíticas implementadas e, acima de tudo, na solução proposta para superar a relação de dependência. Por razões óbvias, a vertente marxista utiliza conceitos derivados da política econômica marxista. No entanto, ao contrário de Marx, eles argumentam que o desenvolvimento do capitalismo, nos países dependentes, não demonstra as características progressivas que existem nos países dominantes. Por conseguinte, alguns autores se referem a essa posição como neomarxis- 
ta. Como solução, os estruturalistas acreditam que é possível superar a dependência ao reformar radicalmente o sistema capitalista através da criação de uma nova ordem econômica internacional (Sunkel, 1990); já para os marxistas, a superação do sistema capitalista rumo a uma ordem mundial socialista é a única solução possível (Cf. Dos Santos, 1972; Marini, 1973).

Teóricos da dependência constituem um grupo bastante eclético. Eles enfatizam fatores distintos para explicar as situações de dependência, mesmo entre as duas vertentes que proponho. Por exemplo, dentro da vertente estruturalista, Sunkel afirma que o aumento das corporações multinacionais, como consequência da substituição de importações em países dependentes, está levando a um processo de desintegração nacional e marginalização de grupos sociais que são deslocados durante esse processo (Cf. Sunkel, 1969). Enquanto isso, Celso Furtado enfatiza os "padrões dependentes de consumo" gerados por essas multinacionais, criando, desse modo, uma estrutura industrial imprópria para países subdesenvolvidos, uma vez que é muito diversificada e muito capital intensiva, portanto, aumentando o excedente populacional e perpetuando a alta concentração de renda, consequentemente, o padrão de consumo dependente (Cf. Furtado, $\infty$ 1973). Dessa forma, o ciclo da dependência econômicas, sociais e políticas.

Na vertente marxista, posso me remeter a Frank, que já mencionei, assim como a The- otonio dos Santos e Ruy Mauro Marini, entre outros (Cf. Frank, 1966; Osorio, 2016). Ele cunhou o famoso termo "o desenvolvimento do subdesenvolvimento", o qual significa que a relação de dependência reproduz o subdesenvolvimento dos países, ao invés de levá-los a um caminho de desenvolvimento sustentável. Dos Santos afirmou que um elemento-chave nas relações de dependência cresce devido à falta de um setor de bens de capitais nos países desenvolvidos (Cf. Dos Santos, 1970). O processo de substituição de importações não habilitou esses países a produzirem suas próprias tecnologias, já que empresas multinacionais preferem manter controle dessas tecnologias nos países-sede, em países desenvolvidos. Logo, os países em desenvolvimento têm se tornado dependentes das importações para ter acesso a maquinarias, equipamentos e outros produtos, bem como para manter a industrialização por substituição de importações e outros setores. Desse modo, a "dependência tecnológica" é um fator-chave para a reprodução de relações de dependência. Como exemplo final dessa vertente da teoria da dependência, eu gostaria de realçar a contribuição de Marini, que destacou a "superexploração do trabalho" pelo capital, que emerge da "troca desigual" entre o mundo desenvolvido e o subdesenvolvido (Cf. Bueno, 2016; Marini, 1973).

Também é possível falar sobre uma vertente caribenha da teoria da dependência, que surgiu principalmente de um grupo de acadêmicos e ativistas ligados à Universidade das Índias Ocidentais. Embora influenciados pelos teóricos estruturalistas e marxistas, eles afirmavam que deveria haver uma adaptação ao contexto dos países caribenhos, que são pequenas economias, com passados coloniais recentes (Cf. Girvan, 1973; Levitt, 2005).

A teoria da dependência foi particularmente influente entre o final dos anos 60 e nos anos 70. Provocou muitos debates e críticas no passado, mas continua relevante atualmente, embora com algumas mudanças como é discutido por Cristóbal Kay e Robert Gwynne (2000) e Ronaldo Munck (Cf. Kay; Gwynne, 2000; 
Munck, 1999). Enquanto a vertente marxista da dependência tendeu a se converter em teoria do sistema-mundo, particularmente no caso de Frank (Cf. Kay, 2006a, 2011), a vertente estruturalista se transformou em neoestruturalista, o que será discutido em seguida.

\section{NEOESTRUTURALISMO E DESEN- VOLVIMENTO ALTERNATIVO}

A contrarrevolução neoliberal em estudos sobre desenvolvimento (Krugman, 1992), que fermentou durante os anos 1970, ganhou impulso na virada da década com a vitória do partido conservador, sob a liderança de Margaret Thatcher em 1979 no Reino Unido e a subsequente eleição de Ronald Reagan em 1981 para a presidência dos Estados Unidos. Ambas as administrações levaram a cabo a agenda neoliberal, que buscava desmantelar muitas das conquistas do estado de bem-estar social e fortalecer as forças impulsionadoras do neoliberalismo em países em desenvolvimento. Com a crise da dívida da década de 1980, que foi particularmente aguda na América Latina, as forças neoliberais se aproveitaram do momento e utilizaram as instituições financeiras internacionais (Banco Mundial e Fundo Monetário Internacional) e os programas de ajuda dos EUA e Reino Unido, entre outros, para impor certas condições para a liberação de crédito e financiamento aos países endividados.

Essa ampla gama de reformas foi batizada de "programa de ajuste estrutural" e levou ao "consenso de Washington", cidade que não somente é sede do Governo dos Estados Unidos e de seu Tesouro, mas também do Banco Mundial, do FMI, do Banco Interamericano de Desenvolvimento e da Organização dos Estados Americanos, todos promotores do neoliberalismo. Entre as reformas exigidas estavam o desmonte do estado desenvolvimentista e das medidas protecionistas do período de substituição de importações, para deixar liberdade total paras as forças do mercado global (Sa-
ad-Filho; Johnston, 2005). Sob a ditadura do general Pinochet (1973-1990), o Chile foi o pioneiro do neoliberalismo (Cf. Valdés, 1995), que acabou se tornando o discurso político dominante em vários países do mundo.

Situada entre as primeiras instituições de estudo sobre desenvolvimento a desafiar o paradigma neoliberal, a CEPAL passou a incluir o Caribe em seu nome e, a partir de 1990 e publicou uma série de livros que estabeleceram sua nova abordagem para o desenvolvimento, evoluindo do estruturalismo, buscando renová-lo e chamando-o de "neoestruturalismo" (Cf. Sunkel, 1993). O texto fundacional do neoestruturalismo é La transformación productiva com equidad (1990), cujo autor intelectual foi Fernando Fajnzylber (Cf. Torres, 2006). Os neoestruturalistas tentaram "se acertar" com o desaparecimento do estruturalismo e da teoria da dependência, o surgimento de países recém-industrializados, os desafios da globalização, e o aumento da pobreza e da desigualdade na América Latina, como consequência de políticas neoliberais.

Os elementos-chave do neoestruturalismo podem ser resumidos da forma apresentada a seguir.

- A teoria muda sua ênfase em relação ao estruturalismo, de um desenvolvimento "interno" para um desenvolvimento "de dentro" e prioridades domésticas seletivas, mas, cada vez mais, em áreas do mercado global que oferecem as melhores oportunidades para o desenvolvimento estratégico e de longo prazo do país. O comércio internacional se tornaria, portanto, um setor mais importante que no passado, pois seria visto como mais dinâmico que o mercado doméstico. À questão de troca desigual foi dada menor prioridade ou sequer era mencionada.

- Isso exigiu a transformação da estrutura de produção do país, passando das exportações tradicionais de matérias-primas para as exportações com maior valor agregado e, especialmente, para as exportações industriais. Em vez de continuar com as vantagens com- 
parativas do país, o estado agora foi encarregado de desenvolver suas "vantagens competitivas". Logo, o estado deveria expandir a educação, melhorar o padrão de vida e promover a tecnologia e a inovação.

- Para alcançar esse objetivo, era necessário um estado mais ágil, competente, pragmático, hábil e catalisador, em comparação com um estado clientelista, burocrático e grande demais para poder encorajar o setor privado a buscar as novas oportunidades da globalização, bem como ser capaz de adaptar suas políticas de acordo com as circunstancias internas e extensas. O estado não necessitava mais criar empresas estatais. Ao invés disso, poderia estabelecer parcerias público-privadas quando fosse a forma mais apropriada de incentivar investimentos, empreendedorismo e atividades de alto valor econômico. Em suma, um estado desenvolvimentista "leve" (Cf. Petras; Veltmeyer, 2007).

- Uma visão mais flexível e aberta do mercado foi assumida. Logo, ao invés de usar medidas protecionistas, controle de preços, controle de taxa de câmbio de maneira clientelista e indiscriminada, o objetivo agora era "governar o mercado" de uma maneira premeditada, com o objetivo de alcançar certas metas de desenvolvimento, em certo período de tempo, para que a intervenção do mercado não se tornasse impregnada. Portanto um olho estava sempre atento aos sinais do mercado.

- Para estar em uma posição melhor face ao mercado global, neoestruturalistas propuseram uma política de "regionalismo aberto", por exemplo, com acordos de troca e investimento entre países da região, mas com a visão de que deveria ser a região a negociar com outros países e regiões do mundo. Assim, os acordos bilaterais com os países deveriam ser evitados, pois um único país latino-americano, especialmente quando fossse o menor, teria pouca capacidade de barganha ao lidar com países ricos e grandes.

- Por fim, como os mercados tendem a fomentar desigualdades, especialmente os neoli- berais, o Estado deveria encorajar medidas que promovessem a equidade. Um dos slogans foi "crescer com equidade", já que, sem crescimento, seria difícil financiar medidas de equidade. A conquista da inclusão, da coesão social e da redução da pobreza foi, portanto, uma parte importante da agenda desenvolvimentista neoestruturalista.

O neoestruturalismo foi atacado por neoliberais, assim como setores da esquerda radical. Os neoliberais o veem como muito estatista, intervencionista e muito ligado ao desgastado e desacreditado estruturalismo. Já a visão da esquerda radical o analisa como se fosse uma versão nova, talvez pragmaticamente mais humana, do neoliberalismo, chegando perto de ser chamado de um "pós-consenso de Washington", em que medidas específicas de mitigação social e de pobreza foram introduzidas nas primeiras versões do "Consenso de Washington", considerado muito severo (Cf. Leiva, 2008).

Enquanto poucos governos latino-americanos admitem abertamente sofrer influência das idéias neoestruturalistas, ou sequer tentam seguir aspectos de uma estratégia de desenvolvimento neoestruturalista, ela é muito mais influente do que na revisão da literatura de desenvolvimento, onde raramente é mencionada, exceto nos escritos da CEPAL (Cf. Bárcenas; Prado, 2016; Gwynne; Kay, 2004). A maioria dos governos de esquerda e centro-esquerda, na América Latina, quando se trata de ir além da retórica e examinar a implementação de políticas públicas, é bastante influenciada pelo pensamento neoestruturalista, mesmo aqueles governos que proclamam seguir caminhos alternativos ou pós-desenvolvimentistas, como o "Buen vivir" (Equador) ou o "Vivir bien” (Bolívia). O que pode ser ainda mais surpreendente é que, em alguns casos, suas políticas são ainda menos radicais do que aquelas propostas pelos neoestruturalistas, os quais são, com frequência, rejeitados pelos críticos à esquerda, por serem reformistas e não irem além do neodesenvolvimentismo. Enquanto os governos de esquerda conseguem reduzir significativamente a pobreza e promover a inclusão social, eles não consegui- 
ram mudar a matriz produtiva; ao invés disso, reforçaram uma agenda de desenvolvimento insustentável e neoextrativista (Cf. Acosta, 2013; Veltmeyer; Petras, 2014).

\section{CONCLUSÕES}

Neste artigo, destaquei algumas contribuições para os estudos críticos sobre desenvolvimento que surgiram na América Latina (Cf. Munck, 2013). Estou ciente de que não tratei de todas elas, porém eu espero ter focado nas mais relevantes. O que considero marcante e desejo enfatizar é a habilidade de alguns pensadores, acadêmicos e ativistas de virar de cabeça para baixo a ortodoxia dominante, ao perceber que as teorias, vindas principalmente dos países desenvolvidos, não eram capazes de explicar as complexidades dos países em desenvolvimento, principalmente na América Latina.

Mariátegui e teóricos da dependência marxista foram além das interpretações dogmáticas do marxismo e buscaram desenvolver interpretações criativas sobre a realidade latino-americana. Prebisch e os estruturalistas, enquanto isso, desafiaram a ortodoxia econômica e as teorias sobre desenvolvimento e criaram uma interpretação alternativa da dinâmica do sistema-mundo. Ambas as teorias críticas latino-americanas sobre o desenvolvimento buscaram transformar o sistema capitalista existente, por meios reformistas ou revolucionários, para alcançar seus respectivos objetivos. Esses objetivos ainda não foram conquistados (Cf. Petras; Veltmeyer, 2009). Por isso, destaco, finalmente, a relevância da continuidade dos estudos críticos sobre o desenvolvimento, a necessidade de desenvolvê-los ainda mais e de promover sua relevância para os movimentos sociais e organizações que lutam por um mundo melhor ( Cf. Seabra, 2016b).

Recebido para publicação em 02 de abril de 2018 Aceito em 13 de maio de 2018

\section{REFERÊNCIAS}

ACOSTA, A. 'Extractivism and neoextractivism: two sides of the same curse'. In: LAND, M.; MOKRANI, D. (Ed.). Beyond development: alternative visions from Latin America. Quito: Fundación Rosa Luxemburg, 2013. p. 61-86.

BÁRCENAS, A.; PRADO, A. (Ed.). Neostructuralism and heterodox thinking in Latin America and the Caribbean in the early twenty-first century. Santiago: ECLAC, 2016.

BUENO, F. M. 'Presente, passado e future do capitalism brasileiro: o debate da obra de Ruy Mauro Marini'. In: SEABRA, R. L. (Ed.). Dependência e Marxismo: contribuições ao debate Crítico Latino-americano. Florianópolis: Editora Insular, 2016.

CARDOSO, F. H. 'Dependency and development in Latin America'. New left review, v. 74, p. 83-95, 1972.

'Associated dependent development: theoretical and practical implications'. In: STEPAN, A. (Ed.). Authoritarian Brazil: origins, policies and future. Yale: Yale University Press, 1973. p. 142-176.

COMISSÃO ECONÔMICA PARA A AMÉRICA LATINA DAS NAÇÕES UNIDAS (CEPAL). Changing production patterns with social equity. Santiago: United Nations Economic Commission for Latin America and the Caribbean, 1990.

COTLER, J. 'The mechanics of internal domination and social change in Peru', Studies in comparative international development, v. 3, n. 12, 1967.

DOS SANTOS, T. dos. Dependencia y cambio social. Santiago: Centro de Estudios Socio-Económicos, 1970.

Socialismo o Fascismo: el nuevo carácter de la dependencia y el dilema Latinoamericano. Santiago: Ediciones PLA, 1972.

DOSMAN, E. J. The life and times of Raúl Prebisch 19011986. Montreal: McGill-Queen's University Press, 2008.

FITZGERALD, E. V. K. 'ECLA and the theory of import substituting industrialization in Latin America'. In: CÁRDENAS, E.; OCAMPO, J. A.; THORP, R. (Ed.). An Economic history of twentieth-century Latin America: industrialization and the State in Latin America: the postwar years. Nova York: Palgrave, 2000. v. 3.

FRANK, A. G. 'The Development of underdevelopment'. Monthly review, v. 18, n. 4, p. 17-31, 1966.

FURTADO, C. Development and underdevelopment: a structural view of the problems of developed and underdeveloped countries. Berkeley: University of California Press, 1964.

.'The concept of external dependence in the study of underdevelopment'. In: WILBER, C. K. (Ed.). The political economy of development and underdevelopment. Nova York: Random House, 1973. p. 118-123.

GIRVAN, N. "The development of dependency economics in the Caribbean and Latin America. Social and economic studies, v. 22, n. 1, p. 1-33, 1973.

GONZÁLEZ CASANOVA, P. 'Internal colonialism and national development'. Studies in comparative international development, v. 1, n. 4, p. 27-37, 1965.

GWYNNE, R. N.; KAY, C. (Ed.). Latin America transformed: globalization and modernity. Londres: Hodder Education, 2004.

HIRSCHMAN, A. O. 'Ideologies of economic development in Latin America'. In: HIRSCHMAN, A. O. (Ed.). Latin American issues: essays and comments. Londres: George Allen \& Unwin, 1961.

KAY, C. Latin American theories of development and underdevelopment. Londres: Routledge, 1989. 
. 'Marxism in Latin America'. In: BOTTOMORE, T.

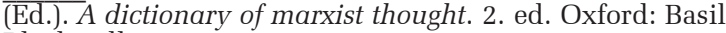
Blackwell, 1991. p. 362-365.

'Celso Furtado: pioneer of structuralist development theory'. Development and change, v. $36, \mathrm{n}$. 6, p. 1201-1207, 2005.

Kay, C. 'André Gunder Frank (1929-2005): pionero de la teoría de la dependencia y de la mundialización', Revista mexicana de Sociología, v. 68, n. 1, p. 181-190, $2006 a$.

'Raúl Prebisch. In: SIMON, D. (Ed.). Fifty key thinkers on development. Londres: Routledge, 2006b. p. 199-205.

'The Latin American structuralist school'. In: KITCHIN, R.; THRIFT, N. (Ed.). International encyclopedia of human geography. Oxford: Elsevier, 2009. v. 6. p. 159-164.

. 'Andre Gunder Frank: "unity in diversity" from the development of underdevelopment to the world system'. New political economy, v. 16, n. 4, p. 523-538, 2011.

KAY, C.; GWYNNE, R. N. 'Relevance of structuralist and dependency theories in the neoliberal period: a Latin American perspective'. Journal of developing societies, v. 16, n. 1, p. 49-69, 2000.

KRUGMAN, P. 'Toward a counter-counterrevolution in development theory'. In: WORLD BANK ANNUAL CONFERENCE ON DEVELOPMENT ECONOMICS, 1992, Washington. Proceedings. Washington, DC: World Bank 1992.

LEIVA, F. I. Latin American neostructuralism: the contradictions of post-Neoliberal Development. Minneapolis: University of Minnesota Press, 2008.

LEVITT, K. Reclaiming development: independent thought and caribbean community. Kingston: Ian Randle Publishers, 2005.

LITTLE, I.; SCITOVSKY, T.; SCOTT, M. Industry and trade in some developing countries: a comparative study. Oxford: Oxford University Press, 1970.

LOMNITZ, L. Networks and marginality: life in a mexican shanty town. Nova York: Academic Press, 1977.

MARIÁTEGUI, J. C. Seven interpretive essays on peruvian reality. Austin: University of Texas Press, 1971.

MARINI, R. M. Dialéctica de la dependencia. Cidade do México: Ediciones Era, 1973.

$\infty$ MUNCK, R. 'Dependency and Imperialism in the new times: a Latin American perspective'. European journal of \& development research, v. 11, n. 1, p. 56-74, 1999.

هั . Rethinking Latin America: development, hegemony, and social transformation. Nova York: Palgrave \& Macmillan, 2013.

i _. 'Critical development theory: results and prospects'. In: VELTMEYER, H.; BOWLES, P. (Ed.). The it essential guide to critical development studies. Nova York: F Routledge, 2018.

$\dot{2}$ MUNCK, R.; O'HEARN, D. (Ed.). Critical development theory: ti contributions to a new paradigm. Londres: Zed Books, 1999.

д. NEDERVEEN-PIETERSE, J. Development theory: के deconstructions / reconstructions. Londres: Sage, 2001.

$>$ NOYOLA, J. 'El desarrollo económico y la inflación en ث̊ México y otros países latinoamericanos'. Investigación económica, v. 16, n. 4, 1956.

क OSORIO, J. 'O Marxismo latino-americano e a teoría da - dependência'. In: SEABRA, R. L. (Ed.). Dependência 蛹 e Marxismo: contribuçôes ao debate crítico Latinoamericano. Florianópolis: Editora Insular, 2016.

PETRAS, J.; VELTMEYER, $\mathrm{H}$. 'The development state in Latin America: whose development? Whose state?' The Uै journal of peasant studies, v. 32, n. 3-4, p. 371-407, 2007.
What's left in Latin America? regime change in new times. Farnham: Ashgate, 2009.

PETRAS, J.; ZEITLIN, M. (Ed.). Latin America: reform or revolution? Nova York: Fawcett, 1968.

QUIJANO, A. 'The marginal pole of the economy and the marginalized labour force'. Economy and society, v. 3, n. 4, 1974.

.'Imperialism and marginality in Latin America'. Latin American perspectives, v. 10, n. 2-3, p. 37-38, 1983.

.'Coloniality of power, eurocentrism, and Latin America'. Nepantla: views from south, v. 1, n. 3, p. 533-580, 2000.

RODRÍGUEZ, O. 'On the conception of the centreperiphery system'. CEPAL review, v. 3, p. 195-239, 1977.

SAAD-FILHO, A.; JOHNSTON, D. (Ed.). Neoliberalism: a critical reader. Londres: Pluto Press, 2005.

SEABRA, R. L. 'Notas metodológicas sobre a anticipação mariateguiana à teoria a dependência'. In: SEABRA, R. L. (Ed.). Dependência e Marxismo: contribuções ao debate crítico Latino-americano. Florianópolis: Editora Insular, 2016a.

'O imperativo da intrepretação própria sobre o desenvolvimento do capitalism Latino-Americano'. In: SEABRA, R. L. (Ed.). Dependência e Marxismo: contribuções ao debate crítico Latino-americano. Florianópolis: Editora Insular, 2016b.

STAVENHAGEN, R. 'Classes, colonialism, and acculturation: essay on a system of inter-ethnic relations in mesoamerica'. Studies in comparative international development, v. 1, n. 6, p. 53-77, 1965.

.'Marginality, participation and agrarian structure in Latin America'. International institute for labour studies bulletin, n. 7, 1970.

Between underdevelopment and revolution: a Latin American perspective. Nova Delhi: Abhinav publications, 1980.

SUNKEL, O. 'Inflation in Chile: an unorthodox approach'. International economic papers, v. 10, p. 107-131, 1960.

'National development policy and external dependence in Latin America'. Journal of development studies, v. 6, n. 1, p. 23-48, 1969.

. 'Big business and "dependencia”: a Latin American view’. Foreign affairs, v. 50, n. 3, p. 517-531, 1972.

'Structuralism, dependency, and institutionalism: an exploration of common ground and disparities'. In: DIETZ, J. L.; JAMES, D. D. Progress toward development in Latin America. Boulder: Lynne Rienner, 1990. p. 29-39.

SUNKEL, O. (Ed.). Development from Within: toward a neostructuralist approach for Latin America. Boulder: Lynne Rienner, 1993.

TOKMAN, V. 'Informal-formal sector relationships: an exploration into their nature'. CEPAL review, n. 5, 1978.

TORRES, M. (Ed.). Fernando Fajnzylber: una visión renovadora del desarrollo en América Latina. Santiago: CEPAL, 2006.

TOYE, J. Dilemmas of development: reflections on the Counter-Revolution in development theory and policy. Oxford: Blackwell, 1987.

TOYE, J.; TOYE, R. The UN and global political economy. Bloomington: Indiana University Press, 2004.

UNITED NATIONS DEPARTMENT OF ECONOMIC AFFAIRS. Economic survey of Latin America 1949. Nova York: UN Department of Economic Affairs, 1951.

VALDÉS, J. G. Pinochet's economists: the Chicago School of Economics in Chile. Cambridge: Cambridge University Press, 1995.

VELTMEYER, H.; PETRAS, J. (Ed.). The new extractivism: a post-neoliberal development model or imperialism of the twenty-first century? Londres: Zed Books, 2014. 


\section{THE LATIN AMERICAN CONTRIBUTIONS TO CRITICAL DEVELOPMENT THEORY}

\section{Cristóbal Kay}

In this article I explore the genealogy of the crucial contribution which Latin American social scientists made to development studies during the second half of the twentieth century. The structuralists, through their centre-periphery paradigm, disputed the conventional theory of international trade which had been proposed the theorists from the North. In turn, dependency theorists critiqued the orthodox interpretations of underdevelopment, such as those proposed by modernization theorists, also mainly from the North. It is important to distinguish between two strands within dependency theory. One emerged from a process of self-criticism by structuralists and the other had its roots in critical Marxism. With the rise of neoliberalism some dependency structuralists developed neostructuralism while some Marxist dependentistas developed worldsystem theory. The ideas of structuralist and dependency thinkers generated fierce debates. They were able to challenge their orthodox and Northerncentric theories and propose an alternative critical theory of development from the South.

KEYwORDS: Structuralism. Internal colonialism. Marginality. Dependency theory. Neostructuralisms.

\section{LES CONTRIBUTIONS DE L'AMÉRIQUE LATINE À LA THÉORIE CRITIQUE DU DÉVELOPPEMENT}

\author{
Cristóbal Kay
}

Dans cet article, j'explore la généalogie de la contribution cruciale que les chercheurs en sciences sociales d'Amérique latine ont apportée aux études sur le développement au cours de la seconde moitié du XXe siècle. Les structuralistes ont contesté la théorie conventionnelle du commerce international qui avait été proposée aux théoriciens du Nord. Les théoriciens de la dépendance ont critiqué les interprétations orthodoxes du sous-développement, telles que celles proposées par les théoriciens de la modernisation, aussi principalement du Nord. Il est important de distinguer deux volets dans la théorie de la dépendance. L'un a émergé d'un processus d'autocritique par les structuralistes et l'autre a ses racines dans le marxisme critique. Avec la montée du néolibéralisme, certains structuralistes dépendants ont développé le néostructuralisme tandis que certains dépendantistes marxistes ont développé la théorie du système mondial. Les idées des penseurs structuralistes et dépendants ont suscité de vifs débats.

Mots CLÉs: Structuralisme. Colonialisme interne. Marginalité. Théorie de la dépendance. Néostructuralisme.

Cristóbal Kay - Professor Emérito do Instituto Internacional de Estudos Sociais (ISS), Erasmus University Rotterdam. Pesquisador Associado do Departamento de Estudos de Desenvolvimento da SOAS, Universidade de Londres. Professor Emérito da FLACSO, Quito, Equador. Fez seus estudos na Universidade do Chile e no Instituto de Estudos de Desenvolvimento da Universidade de Sussex (Ph.D.). Foi pesquisador do Centro de Estudos Sócio Econômicos (CESO) da Universidade do Chile, em Santiago, e depois de 1973, na Universidade de Glasgow e da ISS, em Haia. Em 1979-1980 ele foi professor visitante na Universidade Católica de Lima. Seus interesses de pesquisa estão nos campos de estudos de desenvolvimento e desenvolvimento rural. Autor das teorias latino-americanas de desenvolvimento e subdesenvolvimento. Foi editor do European Journal of Development Research (EJDR) e co-editor da European Review of Latin and Caribbean Studies (ERLACS). Atualmente é editor do Journal of Agrarian Change (JAC). 
